\title{
Gene expression profiling of $A B C$ transporters in dermal fibroblasts of pseudoxanthoma elasticum patients identifies new candidates involved in PXE pathogenesis
}

\author{
Doris Hendig ${ }^{1}$, Thomas Langmann²,3, Sarah Kocken ${ }^{1}$, Ralf Zarbock ${ }^{1}$, Christiane Szliska ${ }^{4}$, Gerd Schmitz², \\ Knut Kleesiek ${ }^{1}$ and Christian Götting ${ }^{1}$
}

Mutations in the $A B C C 6$ gene, encoding the multidrug resistance-associated protein 6 (MRP6), cause pseudoxanthoma elasticum (PXE). This heritable disorder leads to pathological alterations in connective tissues. The implication of MRP6 deficiency in PXE is still unknown. Moreover, nothing is known about a possible compensatory expression of other ATP binding-cassette $(A B C)$ transporter proteins in MRP6-deficient cells. We investigated the gene expression profile of $47 A B C$ transporters in human dermal fibroblasts of healthy controls $(n=2)$ and PXE patients $(n=4)$ by TaqMan low-density array. The analysis revealed the expression of $37 \mathrm{ABC}$ transporter genes in dermal fibroblasts. $A B C C 6$ gene expression was not quantifiable in fibroblasts derived from PXE patients. Seven genes ( $A B C A 6, A B C A 9, A B C A 10, A B C B 5, A B C C 2, A B C C 9$ and $A B C D 2$ ) were induced, whereas the gene expression of one gene ( $A B C A 3)$ was decreased, comparing controls and PXE patients (with at least twofold changes). We reanalyzed the gene expression of selected $A B C$ transporters in a larger set of dermal fibroblasts from controls and PXE patients $(n=6$, each). Reanalysis showed high interindividual variability between samples, but confirmed the results obtained in the array analysis. The gene expression of $A B C$ transporter genes, as well as lineage markers of PXE, was further examined after inhibition of $A B C C 6$ gene expression by using specific small-interfering RNA. These experiments corroborated the observed gene expression alterations, most notably in the $A B C A$ subclass (up to fourfold, $P<0.05$ ). We therefore conclude that MRP6-deficient dermal fibroblasts exhibit a distinct gene expression profile of ABCA transporters, potentially to compensate for MRP6 deficiency. Moreover, our results point to a function for $A B C C 6 / \mathrm{MRP} 6$ in sterol transport, as sterols are preferential regulators of $A B C A$ transporter activity and expression. Further studies are now required to uncover the role of $A B C A$ transporters in PXE.

Laboratory Investigation (2008) 88, 1303-1315; doi:10.1038/labinvest.2008.96; published online 20 October 2008

KEYWORDS: ABCC6; dermal fibroblast; gene expression profiling; MRP6; pseudoxanthoma elasticum; PXE

Progressive calcification and fragmentation of elastic fibers are characteristic hallmarks of pseudoxanthoma elasticum (PXE), which is caused by mutations in the ABCC6 gene encoding the multidrug resistance-associated protein 6 $\left(\mathrm{MRP} 6{ }^{1-6}\right)$. Recently, two different $a b c c 6$ knockout mouse models were generated, that exhibited a PXE phenotype, strengthening $A B C C 6 / \mathrm{MRP} 6$ as the candidate gene for PXE. ${ }^{78}$ MRP6 is a member of the large ATP-binding cassette (ABC) transporter superfamily. To date, $49 \mathrm{ABC}$ transporter genes have been identified as belonging to this family of membrane transporter proteins performing various functions in human cells. The most prominent and well-characterized $\mathrm{ABC}$ transporter proteins are P-gp (ABCB1/MDR1) and $A B C C 1 / \mathrm{MRP} 1$, mediating multidrug resistance in cancer cells (for review see Haimeur et $a l^{9}$ and Deeley et $a l^{10}$ and http://nutrigene.4t.com/humanabc.htm). MRP6 belongs to subfamily C currently consisting of 13 members, of which 9 belong to the MRP family known to be organic anion transporters. Until now, nothing is known about the physiological function of MRP6 and its role in PXE manifestation. The protein is predominantly expressed in the liver and kidney, whereas very low expression has been observed in

\footnotetext{
'Institut für Laboratoriums—und Transfusionsmedizin, Herz-und Diabeteszentrum Nordrhein-Westfalen, Universitätsklinik der Ruhr-Universität Bochum, Bad Oeynhausen, Germany; ${ }^{2}$ Institut für Klinische Chemie und Laboratoriumsmedizin, Universität Regensburg, Regensburg, Germany; ${ }^{3}$ Institut für Humangenetik, Universität Regensburg, Regensburg, Germany and ${ }^{4}$ Dermatologische Klinik, Krankenhaus Bethesda, Freudenberg, Germany

Correspondence: Dr C Götting, PhD, Institut für Laboratoriums—und Transfusionsmedizin, Herz—und Diabeteszentrum Nordrhein-Westfalen, Georgstraße 11,32545 Bad Oeynhausen, Germany.

E-mail: cgoetting@hdz-nrw.de

Received 6 March 2008; revised 15 August 2008; accepted 18 August 2008
} 
tissues primarily affected by PXE, for instance the skin. ${ }^{2,11}$ It was assumed that MRP6 serves as an efflux pump on the basolateral surface of hepatocytes transporting as yet unidentified substrates from the intracellular milieu to the blood. ${ }^{12,13}$ Indeed, several studies reported alterations in systemic blood components in PXE patients and mouse models due to MRP6 deficiency. ${ }^{14-20}$ Accordingly, PXE was assumed to be primarily a metabolic disorder. ${ }^{12,21-23}$ In contrast, results of several studies also point to a local role for $A B C$ C6/MRP6 as expression of the protein was detected in dermal fibroblasts from healthy controls whereas it was found to be absent in fibroblasts from PXE patients. ${ }^{24}$ Moreover, dermal fibroblasts expanded from PXE patients' biopsies exhibited pathological alterations compared to dermal fibroblasts from healthy controls. ${ }^{25}$ These cells have been shown to synthesize abnormal proteoglycans and to exhibit a higher expression of elastin (ELN), which was further associated with pathological assembly of elastic fibers when cultured in the presence of PXE sera. ${ }^{16,26}$ Quaglino et $a^{27}$ reported that PXE fibroblasts have a raised matrix metallopeptidase 2 mRNA and protein expression. In addition, a mild oxidative stress was observed in PXE fibroblasts with higher malondialdehyde levels, increased superoxide dismutase 2 and reduced catalase and glutathione peroxidase activities. ${ }^{28}$ Therefore, it cannot be excluded that also low-level expression of $A B C C 6 / \mathrm{MRP} 6$ plays an important physiological role. MRPs are active in dermal fibroblasts as these cells exhibit a MRP efflux activity that can be blocked by specific inhibitors known to interfere with MRP function. ${ }^{29-31}$ Furthermore, it was reported that PXE fibroblasts have a reduced MRP transporter activity compared to normal dermal fibroblasts. ${ }^{31}$ Beside MRP6, other MRPs have also been reported to be associated with human diseases. Mutations in $A B C C 2 / \mathrm{MRP} 2$ lead to Dubin-Johnson syndrome, whereas mutations in $A B C C 7 / C F T R$ are the cause for cystic fibrosis. A compensatory expression of $A B C C 3 / \mathrm{MRP} 3$ was previously observed in rats suffering from cholestasis due to MRP2 deficiency, as seen in patients with Dubin-Johnson syndrome and Eisai hyperbilirubinemic rats. ${ }^{32,33}$ The question is whether a MRP6 deficiency has an effect on the expression of other ABC transporter proteins. A recent study by Li $e t ~ a l^{34}$ reported no alterations in the gene expression of other $\mathrm{ABC}$ transporter subfamily $\mathrm{C}$ members in $a b c c 6$ knockout mice. The aim of our present study was to investigate the expression profile of $47 \mathrm{ABC}$ transporter genes, as well as the MRP transporter activity of dermal fibroblasts derived from skin biopsies of PXE patients and of healthy controls. Our results will provide new data implying a compensatory role for other $\mathrm{ABC}$ transporter proteins in PXE manifestation. Moreover, we show that the observed alterations in gene expression of other $\mathrm{ABC}$ transporters are associated with MRP6 deficiency due to inhibition of $A B C C 6 / \mathrm{MRP} 6$ synthesis. Finally, we will discuss a possible role for $A B C C 6 / \mathrm{MRP} 6$ in lipid metabolism.

\section{MATERIALS AND METHODS}

\section{Skin Biopsies and Cell Culture Conditions}

Dermal fibroblasts from seven PXE patients were expanded from skin biopsies. The diagnosis of PXE in all patients was consistent with the reported consensus criteria. ${ }^{35,36}$ The status of the PXE patients was determined by the presence of dermal lesions and ocular findings. The dermal lesions were histologically confirmed by the observation of mineralized elastic fibers in biopsy samples following von Kossa staining. The study was approved by the institutional review board and all patients gave their informed consent. In detail: biopsy samples were digested with $0.5 \%$ pronase E (Sigma, Steinheim, Germany) for $30 \mathrm{~min}$, and $1 \%$ collagenase/dispase (Roche, Penzberg, Germany) in Dulbecco's modified essential medium (DMEM) containing 10\% fetal calf serum, $1 \%$ L-glutamine $(200 \mathrm{mM})$ and $1 \%$ antibiotic/antimycotic solution $(100 \times)$ at $37^{\circ} \mathrm{C}$ overnight. Afterward, the samples were washed twice with Dulbecco's phosphate-buffered saline (DPBS) and seeded in DMEM medium including all supplements. Media and supplements were obtained from PAA (Pasching, Austria) and Biowest (Nuaillé, France). Fibroblast cultures were grown out until they reached confluence and were then subcultured once a week with a ratio of 1:3. Dermal fibroblasts from six healthy controls (NHDF) were purchased from Promocell (Heidelberg, Germany), Genlantis (San Diego, USA) and Cambrex (Walkersville, USA). All cultures were checked for fibroblast-specific marker expression (Thy-1; CD90) by antibody staining following immunofluorescence, according to the manufacturer's protocol (Dianova, Hamburg, Germany). Main characteristics of PXE patients and healthy controls are summarized in Table 1. For all experiments subcultures of the 4th to 8 th passage were used. Experiments were done on four different subcultures of each PXE patient and control subject to exclude variability from culture conditions. Measurements were done in duplicate or triplicate for each biological sample. HepG2 cells were maintained in DMEM supplemented with $10 \%$ fetal calf serum, $1 \%$ L-glutamine $(200 \mathrm{mM})$ and $1 \%$ antibiotic/antimycotic solution $(100 \times)$, subcultured with a ratio of $1: 3$ once a week.

\section{ABCC6 Genotyping}

Genotyping of the c.3421C $>$ T. mutation and mutational analysis of $A B C C 6$ was performed as previously described. ${ }^{6}$

\section{Analysis of ABC Transporter Transcript Levels by TaqMan Low-Density Array}

Transcript levels for 47 human $\mathrm{ABC}$ transporters and the reference gene $18 \mathrm{~S}$ rRNA were analyzed by a well-established real-time PCR-based TaqMan low-density array (TLDA), as described. ${ }^{37}$ Total RNA was extracted from $1 \times 10^{6}$ cells using the RNeasy Midi Kit (Qiagen, Hilden, Germany). Genes that were regulated more than twofold $(\geq 2.0$ and $\leq 0.5)$ 
Table 1 Main characteristics of dermal fibroblasts derived from PXE patients and healthy controls used in the present study

\begin{tabular}{|c|c|c|c|c|c|c|c|c|c|}
\hline Sample ID & Gender & $\mathrm{Age}^{\mathrm{a}}$ & $\begin{array}{l}\text { Biopsy } \\
\text { source }\end{array}$ & $\begin{array}{l}A B C C 6 \\
\text { genotype }\end{array}$ & & & Status $^{\mathrm{c}}$ & $\begin{array}{l}\text { Age at } \\
\text { disease onset }^{\mathrm{a}}\end{array}$ & $\begin{array}{c}\text { Number of } \\
\text { involved } \\
\text { organs }\end{array}$ \\
\hline P60F & Female & 58 & Axilla & c.37-1G > A (SSM) & c.37-1G > A (SSM) & & $\mathrm{hm}$ & 56 & 3 \\
\hline P229F & Female & 50 & NA & c.1171A > G (p.R391G) & c.1208C > A (p.A413N) & $\begin{array}{l}\text { c.2252T >A } \\
(\text { p.M751K) }\end{array}$ & cht & NA & NA \\
\hline P265F & Female & 62 & Cervix & c.1132C > T (p.Q378X) & c.3421C>T (p.R1141X) & & cht & 16 & 3 \\
\hline P3M & Male & 57 & Cervix & c.3421C > T (p.R1141X) & c.3883-6G > A (SSM) & & cht & 46 & 5 \\
\hline P128M & Male & 51 & Cervix & $\begin{array}{l}\text { c.3769_3770insC } \\
\text { (p.L1259fsX1277) }\end{array}$ & $\begin{array}{l}\text { c.3769_3770insC } \\
\text { (p.L1259fsX1277) }\end{array}$ & & $\mathrm{hm}$ & 48 & 3 \\
\hline \multicolumn{10}{|c|}{ Healthy controls } \\
\hline F37A & Female & 37 & Abdomen & - & - & - & wt & - & - \\
\hline $\mathrm{F} 42 \mathrm{~A}$ & Female & 42 & Abdomen & - & - & - & wt & - & - \\
\hline $\mathrm{F} 52 \mathrm{C}$ & Female & 52 & Cheek & - & - & - & wt & - & - \\
\hline M2FS & Male & 2 & Foreskin & - & - & - & wt & - & - \\
\hline M45D & Male & 45 & Face & - & - & - & wt & - & - \\
\hline M56D & Male & 56 & Face & - & - & - & wt & - & - \\
\hline
\end{tabular}

hm, homozygote; cht, compound heterozygote; ht, heterozygote; wt, wild type; SSM, splice site mutation; NA, not applicable; ND, nondetected.

${ }^{\mathrm{a}}$ Age in years.

${ }^{\mathrm{b}}$ Nucleotide numbering refers to the cDNA sequence with the A of the ATG translation initiation start site as nucleotide +1 (GenBank accession number NM_001171.2).

${ }^{\mathrm{c}}$ Genotype status.

were considered significantly regulated. ${ }^{37}$ NHDF served as calibrators to which gene expression values of the PXE fibroblasts were compared.

\section{Validation of ABC Transporter Transcript Levels and PXE Lineage Marker Gene Expression by Quantitative Real-Time PCR}

Total RNA was extracted from $1 \times 10^{6}$ cells using the RNeasy Mini kit (Qiagen) according to the manufacturer's instructions and then stored at $-80^{\circ} \mathrm{C}$. The integrity of the RNA samples was checked by assessing ribosomal RNA bands on a denaturing agarose gel. Quantity and quality of the RNA samples were measured spectrophotometrically. Total RNA $(1 \mu \mathrm{g})$ was transcribed to cDNA using oligo $(\mathrm{dT})$ primers and Superscript II Reverse Transcriptase according to the manufacturer's instructions (Invitrogen, Karlsruhe, Germany). cDNA (equivalent to 12.5 or $25 \mathrm{ng}$ of total RNA) served as a template for measurement of mRNA levels in quantitative real-time PCR (qPCR). Exon-intron-boundary-spanning PCR primers covering the major transcript forms were designed according to the published mRNA sequences
(Table 2). QPCRs were performed using the Platinum SybrGreen PCR Supermix UDG kit from Invitrogen on Eppendorf Mastercycler Realplex ${ }^{2}$ System (Hamburg, Germany). PCR conditions were: $120 \mathrm{~s}$ incubation at $55^{\circ} \mathrm{C}, 120 \mathrm{~s}$ incubation at $95^{\circ} \mathrm{C}$, followed by 45 cycles of degradation at $95^{\circ} \mathrm{C}$ for $10 \mathrm{~s}$, primer-specific annealing for $15 \mathrm{~s}$ (Table 2), elongation and detection of the amplicon at $72^{\circ} \mathrm{C}$ for $20 \mathrm{~s}$. Finally, a melting curve analysis of the amplicon was performed. Specificity of the amplicon was verified by standard methods. Data were analyzed using the method of Vandesompele et al to minimize interindividual sample variability. ${ }^{38}$ Initially, we defined the number of housekeeping genes necessary for accurate normalization by analyzing different housekeeping genes using Genorm software. ${ }^{38}$ Then, a normalization factor was determine by calculating a geometric mean of the expression values from three housekeeping genes $(\beta-2$-microglobulin $=\beta-2 \mathrm{~m}$, glyceraldehyde3 -phosphate dehydrogenase $=$ GAPDH, hypoxanthine phosphor-ribosyltransferase $1=$ HPRT1). Relative expression values were calculated by considering PCR efficiency and dividing by the normalization factor. 
Table 2 Primer annotation and sequence, GenBank accession number, annealing temperature, amplicon size and melting temperature used in quantitative real-time PCR

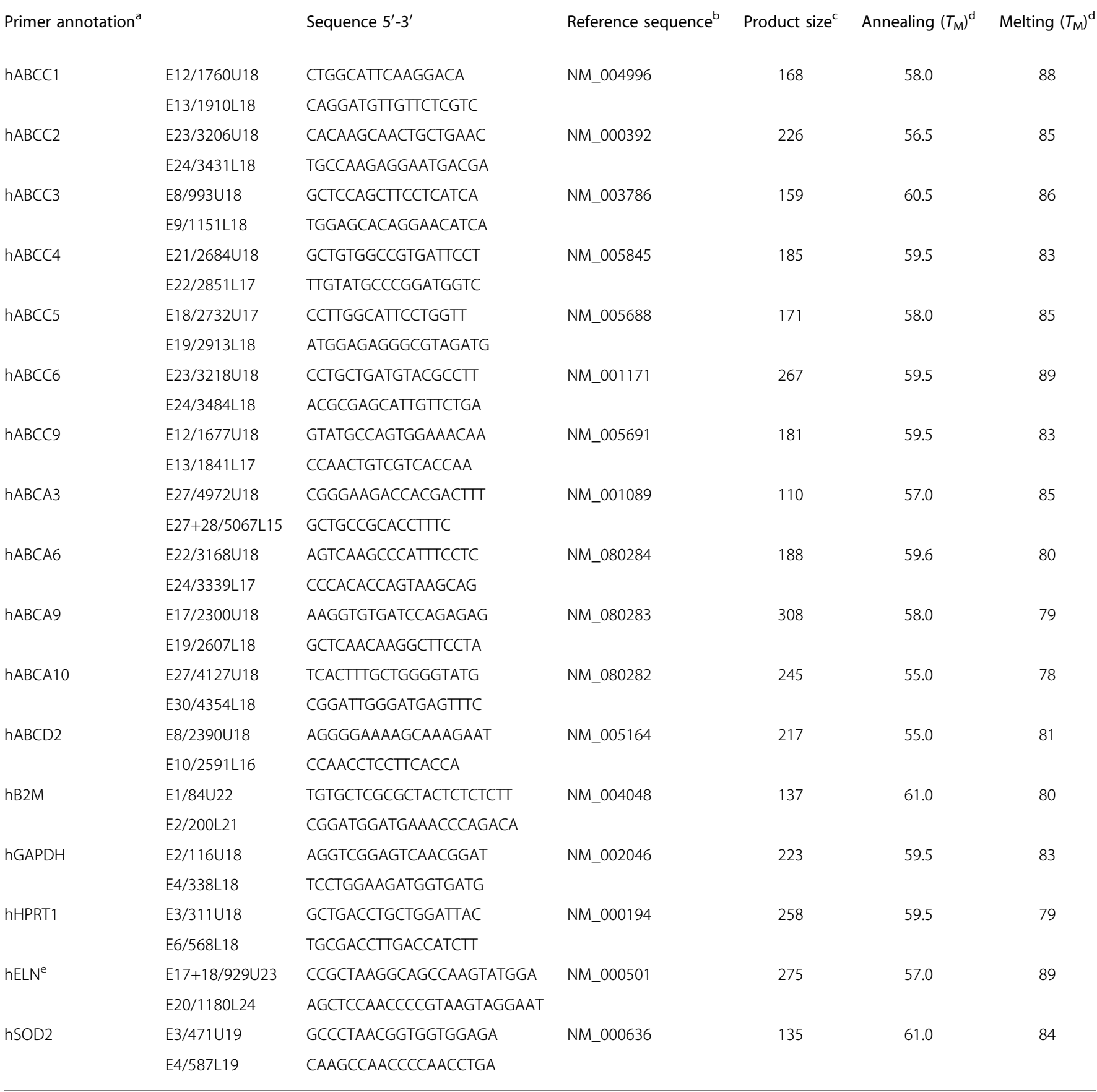

\footnotetext{
${ }^{a}$ Genes were annotated to the nomenclature used in GenBank. Target exons and sequence positions are presented, whereas numbering refers to the cDNA sequence with the A of the ATG translation initiation start site as nucleotide +1 .

$\mathrm{b}$ Reference sequence taken from GenBank. Accession numbers are presented (September 2007).

${ }^{\mathrm{C}}$ Annealing temperature in ${ }^{\circ} \mathrm{C}$.

${ }^{\mathrm{d}}$ Melting temperature of the amplicon in ${ }^{\circ} \mathrm{C}$.

${ }^{\mathrm{e}}$ Primer sequences were taken from RT Primer database (http://medgen.ugent.be/rtprimerdb/).
}

Measurement of MRP Efflux Activity by Flow Cytometry Functional activity of MRPs was measured by quantifying calcein efflux as recently described. ${ }^{31}$ The principle of the assay in brief: cells were loaded with $0.1 \mu \mathrm{M}$ of the nonfluorescent membrane-permeable calcein-acetoxymethyl (caAM) ester for $30 \mathrm{~min}$ at $37^{\circ} \mathrm{C}$. The AM ester is cleaved by 
Table 3 Sequences of used $A B C C 6$-specific siRNA-oligo and targeting sites

\begin{tabular}{lllll}
\hline siRNA oligonucleotide & siRNA ID & Target site $^{\mathrm{b}}$ & Sense $^{c}$ & Antisense $^{c}$ \\
1 & 118143 & Exon 23 & CCCAUUGGUCACCUGCUAAtt & UUAGCAGGUGACCAAUGGGtg \\
2 & 106395 & Exon 21 & GGAAAGGACAGCAUCCAAUtt & AUUGGAUGCUGUCCUUUCCtg \\
3 & 106396 & Exon 21 & GGACAGCAUCCAAUACGGCtt & GCCGUAUUGGAUGCUGUCCtt \\
Silencer negative control & $\# 1$ siRNA & NA & NA & NA \\
\hline
\end{tabular}

NA, not applicable.

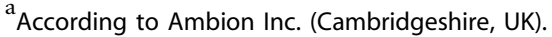

${ }^{b}$ Reference sequence: GenBank accession number NM_001171.

'Sequence $5^{\prime}-3^{\prime}$.

intracellular esterases to release the fluorochrom calcein (ca). Calcein is a specific substrate for MRPs, thus allowing MRP efflux activity to be determined. The cells were washed twice with DPBS afterward and then incubated at $37^{\circ} \mathrm{C}$ in DMEM depleted of FCS. Calcein efflux was quantified after 0, 60, 120, 240 and $360 \mathrm{~min}$ using Epics XL flow cytometer (Beckman Coulter, Krefeld, Germany). Data are presented as remaining intracellular calcein (cellular fluorescence) at time point $360 \mathrm{~min}\left(\%\right.$ intracellular $\mathrm{ca}=\left((\mathrm{ca})^{0 \mathrm{~min}}-(\mathrm{ca})^{360 \mathrm{~min}}\right) /$ $\left.(\mathrm{ca})^{0 \min } \times 100\right)$.

\section{Silencing of $A B C C 6 / \mathrm{MRP} 6$ Expression Using $A B C C 6-S p e c i f i c$ Small-Interfering RNA}

$A B C C 6$-specific small-interfering RNA (siRNA) and FAMlabeled control siRNA oligonucleotides were purchased from Ambion (Cambridgeshire, UK; Table 3). NHDFs and PXE fibroblasts were reverse transfected using $4 \mu \mathrm{l} / \mathrm{ml}$ Lipofectamine 2000 (Invitrogen). Medium was replaced $12 \mathrm{~h}$ past transfection after washing cells twice with DPBS.

\section{Data and Statistical Analysis}

All values are given as mean \pm s.e.m. Normality testing for Gaussian distribution of values was performed using Kolmogorov-Smirnov test. Statistical analysis was performed using Student's $t$-test and Mann-Whitney $U$-test where appropriate. $P$-values of less than 0.05 were considered significant. All tests were executed with GraphPad Prism 4.0 (GraphPad Prism Software, San Diego, CA, USA).

\section{RESULTS}

\section{ABCC6 Genotyping}

$A B C C 6$ genotypes for the seven PXE patients investigated in the present study are shown in Table 1 . Two patients were found to carry one ABCC6 mutation in homozygous state (P60F and $\mathrm{P} 128 \mathrm{M})$. Three patients were identified as being carriers of two different $A B C C 6$ nonsense or splice-site mutations and one patient $(\mathrm{P} 229 \mathrm{~F})$ was identified as carrying two missense mutations revealing a compound heterozygous status. Patient P308M revealed a novel 14-bp insertion in the promoter region in addition to a nonsense ABCC6 mutation.
We failed to detect a second $A B C C 6$ mutation for patient P341M.

\section{Gene Expression Profile of ABC Transporter Genes in NHDFs}

Characterization of the $\mathrm{ABC}$ transporter gene expression profile revealed 37 genes to be expressed in dermal fibroblasts from healthy controls $(n=2)$ and PXE patients $(n=4$, Table 4). NHDFs revealed high expression levels $\left(\Delta C_{\mathrm{t}} 12-16\right)$ for $A B C-A 1, A 2, A 5, A 6, B 7, B 8, B 9, B 10, C 1, C 4, C 9, D 1, D 3$, D4, E1, F1, F2, F3 and TAP1 and 2. Medium expression values $\left(\Delta C_{\mathrm{t}} 16.5-20\right)$ were observed for $A B C-A 3, A 4, A 7, A 8$, $A 9, A 10, B 4, B 6, C 3, C 5, C 10, D 2$ and G2. Low expression $\left(\Delta C_{\mathrm{t}} 20.5-25\right)$ was noticed for $A B C-B 5, C 2, C 6$ and $G 4$. TLDA analysis detected no gene expression for $A B C-A 12$, $A 13, B 1, B 11, C 7, C 8, C 11, G 1, G 5$ and $G 8$ in NHDFs.

\section{NHDF-Specific Gene Expression Profile of ABC Transporters Compared to HDFs of PXE Patients}

No $A B C C 6$ transcripts were quantifiable in fibroblast samples from PXE patients by TLDA analysis. Seven genes were found to be expressed more than twofold higher in PXE patients' fibroblasts (Table 4, depicted in dark gray). These include $A B C-A 6, A 9, A 10, B 5, C 2, C 9$ and $D 2$. The relative mRNA expression of $A B C A 3$ was found to be twofold reduced $(\leq 0.5$-fold $)$ in the PXE patient's samples.

\section{Validation of Altered ABC Transporter Transcript Levels Due to $A B C C 6 / M R P 6$ Deficiency by Quantitative Real-time PCR}

To verify the observed mRNA expression differences, we developed real-time PCR assays for selected members of the $\mathrm{ABCC}$ and $\mathrm{ABCA}$ subclasses, as well as for $A B C D 2$, and reanalyzed gene expression in a larger group of PXE patients and healthy controls (each $n=6$ ). Samples of patient P60F were exchanged with samples of patient P308M in this analysis, due to a lack of material.

We developed a real-time PCR assay that permits relative quantification of ABCC6 mRNA expression. Our assay detects very low levels of ABCC6 mRNA without amplification 
Table 4 Gene expression profile of ABC transporters in dermal fibroblasts of healthy controls and PXE patients ${ }^{\mathrm{a}}$

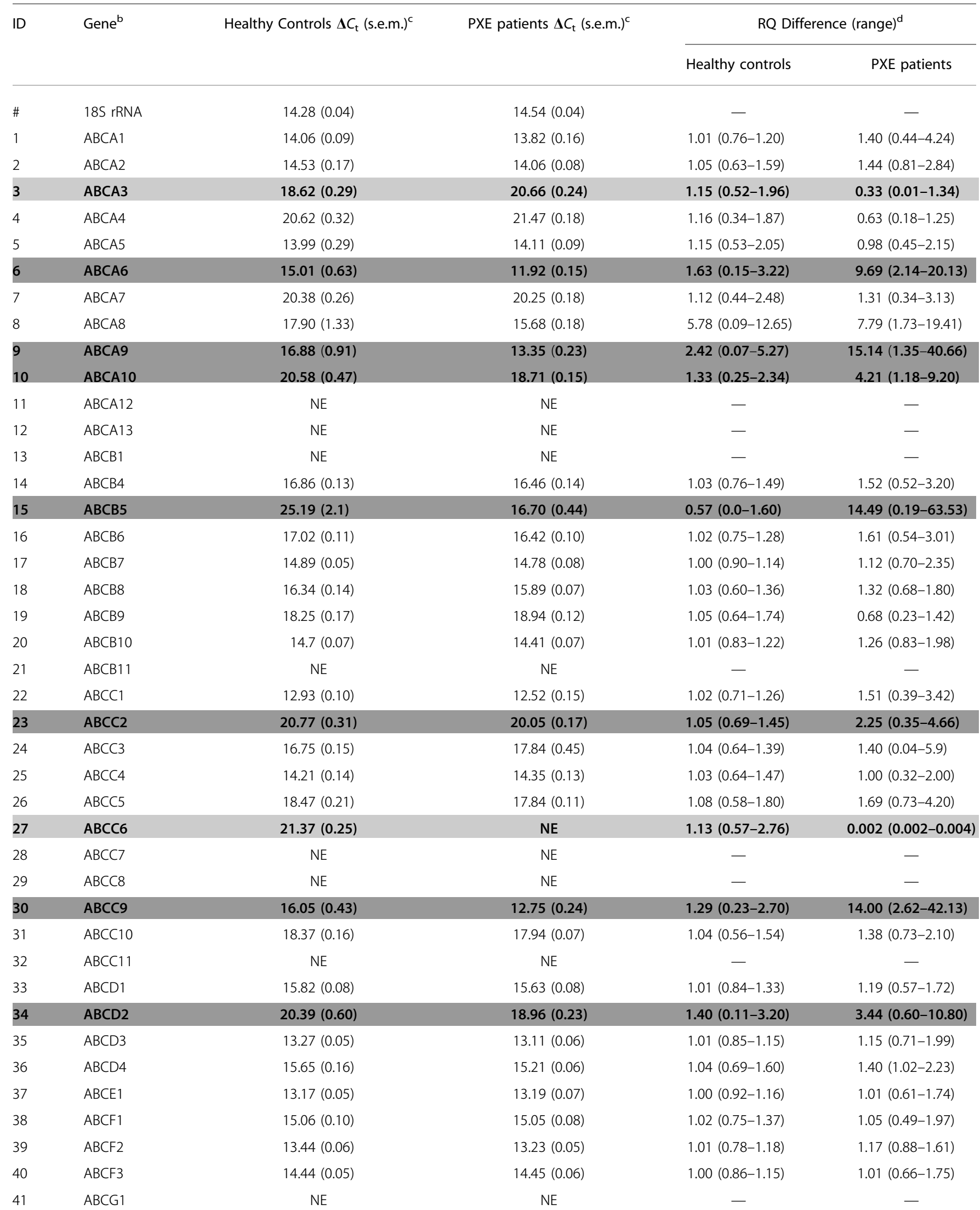


Table 4 Continued

\begin{tabular}{|c|c|c|c|c|c|}
\hline \multirow[t]{2}{*}{ ID } & \multirow[t]{2}{*}{ Gene $^{b}$} & \multirow[t]{2}{*}{ Healthy Controls $\Delta C_{\mathrm{t}}{\text { (s.e.m. })^{c}}^{c}$} & \multirow[t]{2}{*}{ 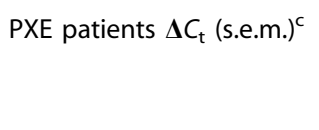 } & \multicolumn{2}{|c|}{ RQ Difference (range) ${ }^{d}$} \\
\hline & & & & Healthy controls & PXE patients \\
\hline 42 & $A B C G 2$ & $18.91(0.24)$ & $19.55(0.21)$ & $1.10(0.52-2.04)$ & $0.87(0.22-3.11)$ \\
\hline 43 & ABCG4 & $20.96(0.29)$ & $21.11(0.28)$ & $1.16(0.64-2.09)$ & $1.25(0.12-4.02)$ \\
\hline 44 & ABCG5 & $\mathrm{NE}$ & $\mathrm{NE}$ & - & - \\
\hline 46 & TAP1 (ABCB2) & $16.22(0.10)$ & $15.67(0.06)$ & $1.02(0.72-1.29)$ & $1.50(0.97-2.42)$ \\
\hline 47 & TAP2 (ABCB3) & $15.62(0.09)$ & $15.50(0.08)$ & $1.01(0.82-1.26)$ & $1.14(0.59-1.91)$ \\
\hline
\end{tabular}

$\mathrm{NE}$, not expressed; PXE, pseudoxanthoma elasticum.

${ }^{a}$ Genes that are regulated more than twofold $(\geq 2.0$ or $\leq 0.5)$ are considered as significantly regulated. Induced genes are depicted in dark gray, downregulated genes in light gray.

${ }^{\mathrm{b}}$ Gene annotation according to the Human ATP-binding Cassette Transporter TaqMan Low-Density Array. ${ }^{37}$

${ }^{\mathrm{c}} \Delta C_{\mathrm{t}}$ values values were calculated by normalization to the expression value of $18 \mathrm{~S}$ rRNA.

${ }^{d}$ Gene expression values were normalized to the expression value of $18 \mathrm{~S}$ rRNA and calculated based on the comparative cycle threshold $\left(C_{\mathrm{t}}\right)$ method $\left(2-\Delta \Delta C_{\mathrm{t}}{ }^{37,54}\right)$. NHDF served as calibrators to which gene expression values of the PXE fibroblasts were compared.
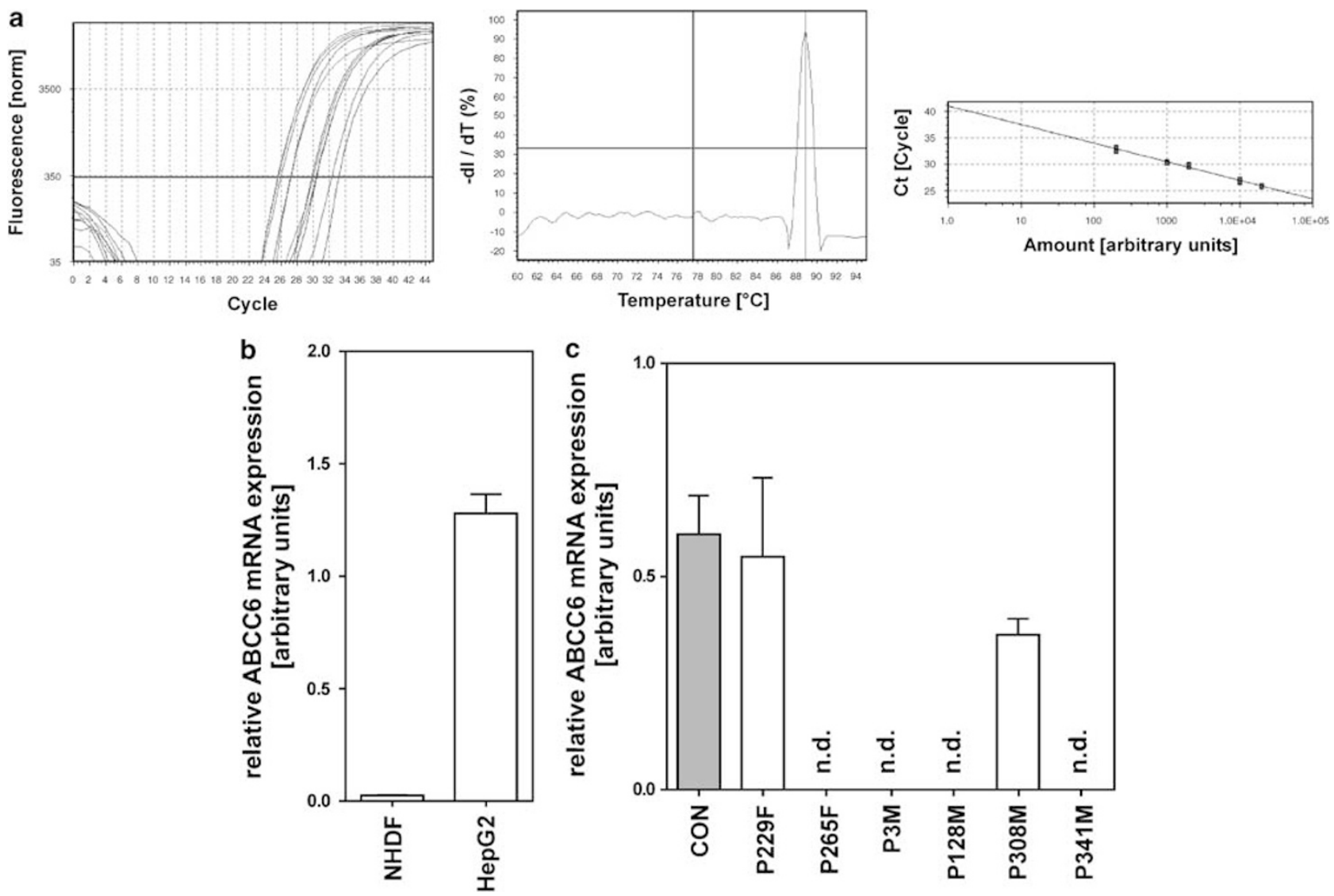

Figure 1 Quantification of ABCC6 mRNA expression. (a) Quantitative real-time PCR assay for detection of human ABCC6 transcripts. The figure shows the amplification plot, a corresponding melting curve of the amplicon and a standard curve generated with diluted NHDF cDNA (Slope -3.51; PCR efficiency 1.93). (b) Validation of the assay with cDNA synthesized from RNA samples of NHDF and HepG2 cells. (c) Quantification of ABCC6 mRNA expression in HDFs from healthy controls (CON, gray column; $n=6$ ) and PXE patients (white columns). Data are presented in arbitrary units as means with corresponding standard error; n.d.: not detectable. 

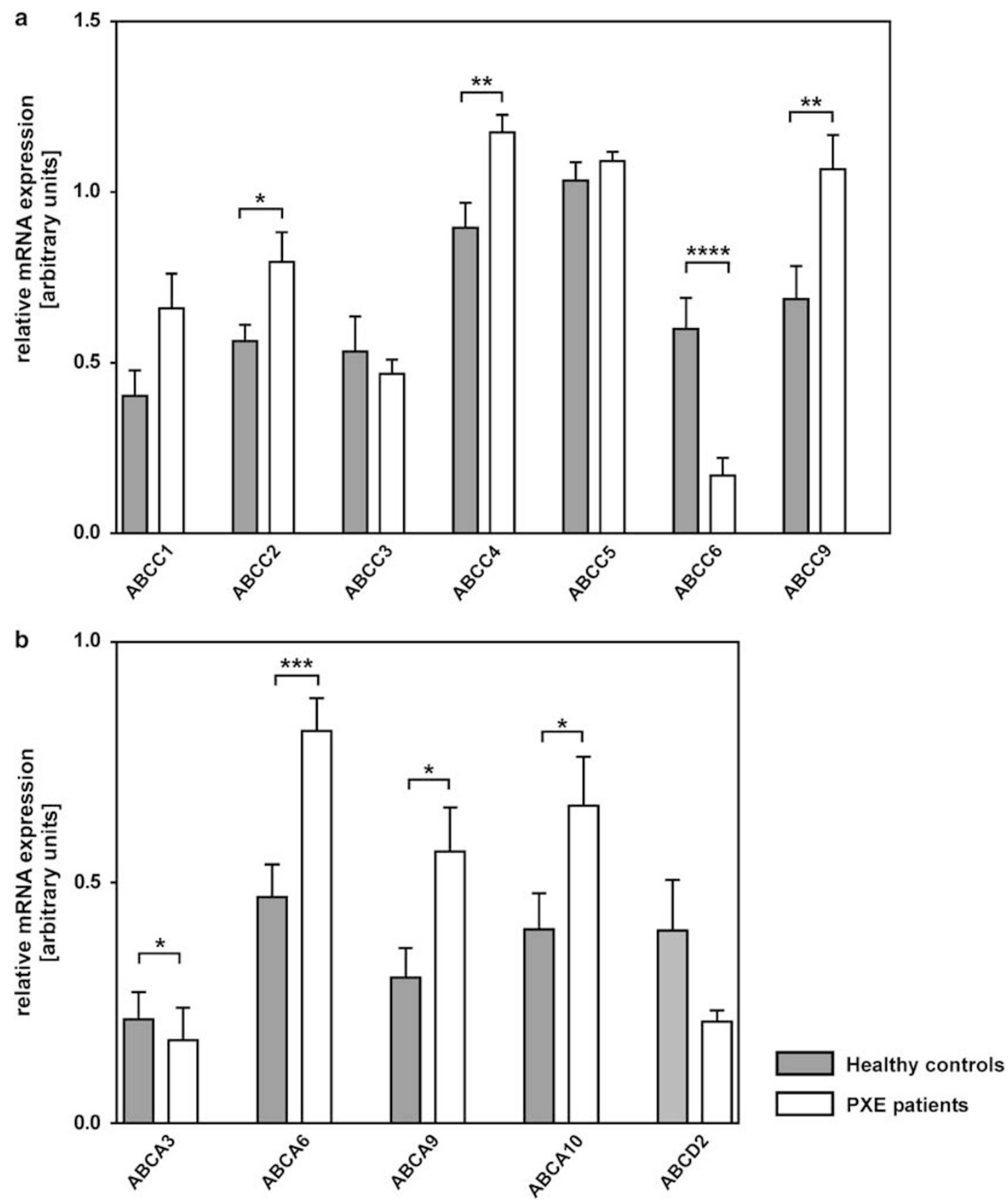

Figure 2 Validation of $A B C$ transporter transcript levels by quantitative real-time PCR. (a) Validation of $A B C C$ subclass members mRNA expression by quantitative real-time PCRs in dermal fibroblasts derived from skin biopsies from PXE patients (white columns) and healthy controls (gray bars; $n=6$, each). (b) Validation of $A B C A$ subclass members and $A B C D 2$ mRNA expression by quantitative real-time PCRs in dermal fibroblasts derived from skin biopsies from PXE patients and healthy controls $\left(n=6\right.$, each). Data are presented in arbitrary units as means with corresponding standard error. ${ }^{\star} P<0.05$; ${ }^{* * P}<0.01$; ${ }_{* * * P}<0.001 ;{ }^{* * * * P}<0.0001$

of competing primer dimers (Figure 1a). To verify our assay, we also analyzed $A B C C 6$ mRNA expression in HepG2 cells, a hepatocarcinoma cell line. ABCC6 mRNA expression levels were expressed 50-fold higher in HepG2 cells compared to NHDFs (Figure 1b). We found significantly lower ABCC6 mRNA expression in PXE patients compared to healthy controls $(0.60 \pm 0.09$ and $0.17 \pm 0.05$, respectively, $P<0.0001$; Figure 2a). No $A B C C 6$ transcripts were quantifiable in pa- tients P265F, P3M, P128M and P341M (Figure 1c). Very low but clearly detectable $A B C C 6$ mRNA levels were measured in PXE patients $\mathrm{P} 229 \mathrm{~F}$ and $\mathrm{P} 308 \mathrm{M}$.

The mRNA expression of the selected other $\mathrm{ABC}$ transporter genes were highly variable between the analyzed individuals but reflect the findings of the TLDA analysis. We found moderately but significantly higher $A B C C 2, A B C C 4$ and $A B C C 9$ mRNA expression in PXE patients (Figure 2a). 


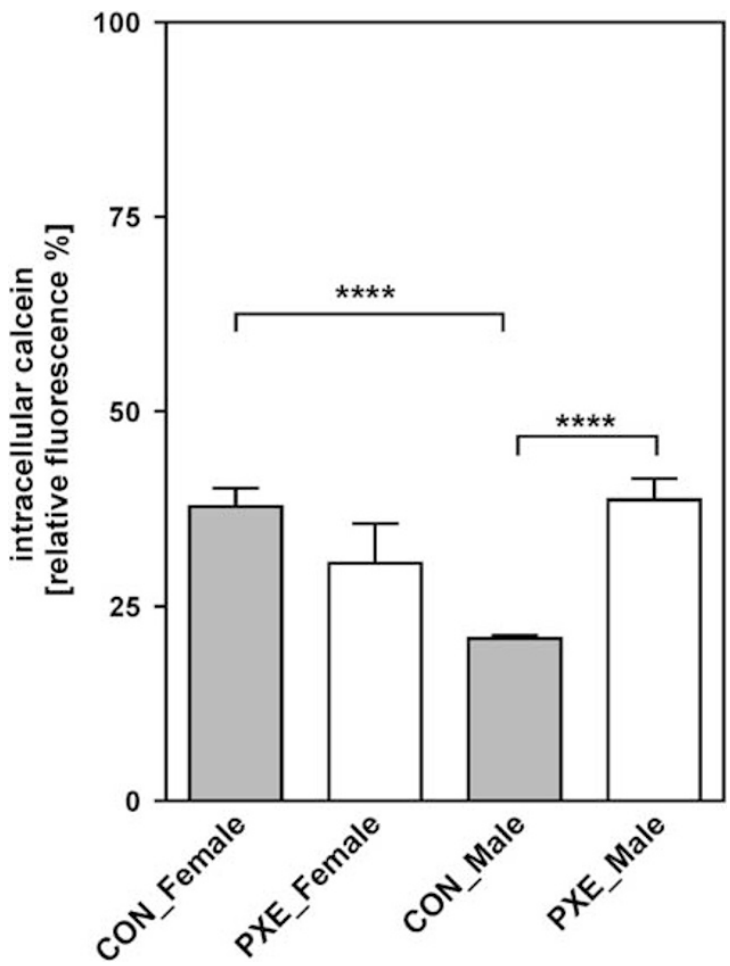

Figure 3 Analysis of MRP efflux activity of HDFs from healthy controls (gray bars) and PXE patients (white bars). Male HDFs show higher efflux rates than female HDFs. Male PXE patients exhibited a higher accumulation of calcein compared to male HDFs. Data are presented as remaining intracellular calcein (fluorescence) in $\%$ from default values at time point 0 min. $\mathrm{CON}=$ healthy controls. ${ }^{* * * P}<<0.0001$.

Significantly higher gene expression of $A B C A 6, A B C A 9$ and $A B C A 10$ was detected in the patient's samples as already observed in the TLDA analysis (Figure 2b). ABCA3 transcript levels were moderately but significantly reduced in PXE patients $(P<0.05)$. Analysis of $A B C D 2$ mRNA expression revealed no significant difference comparing control and PXE fibroblasts.

\section{Analysis of MRP Efflux Activity of Control and PXE Patient HDFs}

Analysis of the MRP efflux activity revealed interesting results. We observed that dermal fibroblasts from male subjects exhibit significantly higher efflux rates. MRP efflux activities of dermal fibroblasts from male PXE patients were determined to be significantly reduced compared to male NHDFs $(P<0.0001$, Figure 3$)$. In contrast, the dermal fibroblasts of female PXE patients showed no differences compared to female NHDFs (Figure 3).

\section{Silencing of $A B C C 6 / M R P 6$ Expression by $A B C C 6-S p e c i f i c$ siRNA}

We further examined the influence of MRP6 deficiency through usage of $A B C C 6$-specific siRNA. HDFs from four different donors were transfected with ABCC6-specific siRNA and nonsense siRNA oligonucleotides. Three different
ABCC6-specific siRNA oligonucleotides were tested in preceding experiments (Table 3). ABCC6-specific siRNA oligonucleotides 1 and 2 yielded a knockdown of $A B C C 6$ mRNA expression of more than $90 \%$ (data not shown). ABCC6 mRNA expression was significantly downregulated with $40 \mathrm{nM}$ of $A B C C 6$-specific siRNA oligonucleotide 1 for 48, 96 and $168 \mathrm{~h}$ (Figure 4). Preliminary results demonstrated a reduced MRP efflux activity 168 and $240 \mathrm{~h}$ after transfection, although the reduction was only negligible $(12 \%$ in the female and $\sim 5 \%$ in the male dermal fibroblast cultures compared to the scramble siRNA-transfected control culture, data not shown). Analysis of lineage markers of PXE reflected a PXE phenotype: ELN gene expression was significantly increased by up to 12 -fold after $168 \mathrm{~h}$ incubation time in all four control fibroblast cultures (Figure 5a). Moreover, transcript levels of manganese superoxide dismutase (SOD2) were increased up to threefold (Figure 5b). Next, we analyzed the effect of the ABCC6-specific knockdown on the gene expression of other homologues $\mathrm{ABCC}$ transporter genes. We observed a slight effect of $A B C C 6$-specific siRNA on $A B C C 1$ and $A B C C 4$ at early time points, returning to normal expression values after $168 \mathrm{~h}$ (data not shown). ABCC3 transcript levels remained unaffected throughout the experiment. Moreover, moderately increased transcript levels up to 1.5fold were detected for $A B C C 5$ at all time points analyzed (Figure 6b), whereas a significantly reduced gene expression was observed for $A B C C 2$ and $A B C C 948$ and $96 \mathrm{~h}$ after transfection (Figure $6 \mathrm{a}$ and $\mathrm{b}$ ). We found a significantly elevated gene expression of $A B C A 3, A B C A 9$ and $A B C A 10$ (Figure 7). Gene expression of $A B C A 6$ was significantly reduced at early time points, returning to normal expression values after $168 \mathrm{~h}$ (data not shown). We performed the same experiments with $A B C C 6 / \mathrm{MRP} 6$-deficient cells from PXE patients P265F and P128M (Table 1). This experiments yielded interesting results: we observed similar significantly elevated ELN and SOD2 expression as already seen in the $A B C C 6 /$ MRP6-deficient control fibroblasts (Figure 5). We also found elevated gene expression levels for $A B C A 3$ and $A B C A 10$, whereas transcript levels for $A B C A 9$ were decreased in the silenced PXE fibroblasts at 48 and $96 \mathrm{~h}$, with a moderate increase at time point $168 \mathrm{~h}$ (Figure 7). Moderately increased transcript levels up to 1.5 -fold were detected for $A B C C 5$ at all time points analyzed (Figure $6 \mathrm{~b}$ ). Futhermore, a significantly reduced gene expression was observed for $A B C C 2$ and $A B C C 948$ and $96 \mathrm{~h}$ after transfection (Figure 6a and c).

\section{DISCUSSION}

MRP6 deficiency is the cause for PXE manifestation due to mutations in the $A B C C 6$ gene. To date, little is known about the implication of $A B C C 6 / \mathrm{MRP} 6$ in PXE pathogenesis. $A B C C 6 / \mathrm{MRP} 6$ is one of 49 more or less well-characterized $\mathrm{ABC}$ transporter genes. In the present study we investigated whether MRP6 deficiency leads to an altered gene expression profile of other $A B C$ transporter genes. Several studies 

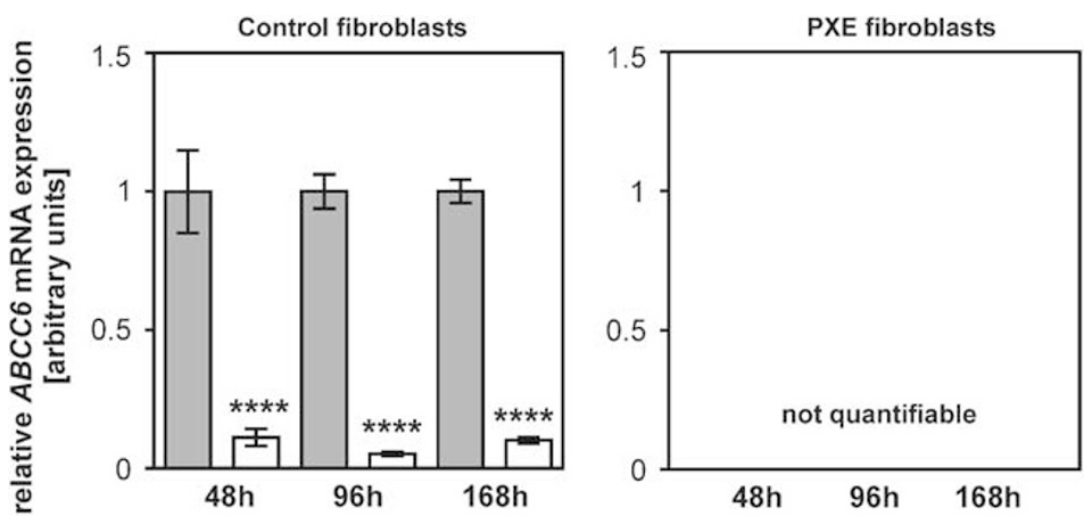

Figure 4 Effect of siRNA-mediated knockdown on ABCC6 gene expression. Gray bars: cell cultures transfected with a scramble siRNA-negative control; white bars: $A B C C 6$-specific siRNA-treated HDFs. Data are presented in arbitrary units as means with corresponding standard error at time points 48,96 and $168 \mathrm{~h}$. Experiments were performed with HDFs from healthy controls $(n=4)$ and PXE fibroblasts $(n=2) .{ }^{* * *} P<0.0001$.

a
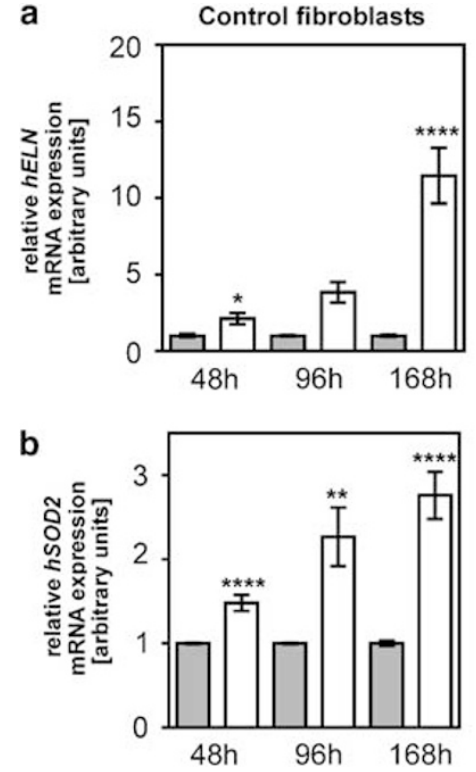

PXE fibroblasts
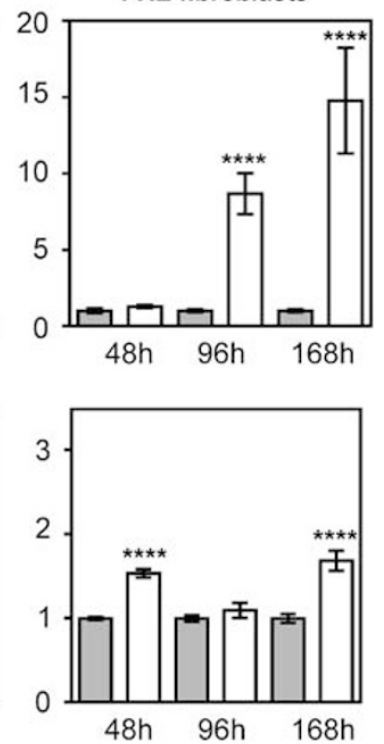

Figure 5 Effect of siRNA-mediated knockdown of $A B C C 6$ gene expression on PXE lineage markers. (a) Relative ELN mRNA expression. (b) Relative SOD2 mRNA expression. Gray bars: cell cultures transfected with a scramble siRNA-negative control; white bars: ABCC6-specific siRNA-treated HDFs. Data are presented in arbitrary units as means with corresponding standard error at time points 48,96 and $168 \mathrm{~h}$. Experiments were performed with HDFs from healthy controls $(n=4)$ and PXE fibroblasts $(n=2) .{ }^{\star} P<0.05$; ${ }^{* *} P<0.01 ;{ }^{* * * *} P<0.0001$.

reported increased expression of related $\mathrm{ABCC} / \mathrm{MRP}$ proteins as a mechanism to compensate a loss of function. ${ }^{32,33}$

We detected altered gene expression of ABCA transporters and the homologous ABCC subfamily members 2, 4 and 9 in dermal fibroblasts derived from PXE patient's skin biopsies. The observed alterations in gene expression and MRP efflux activity reveal high interindividual variability due to different ABCC6 genotypes or genetic background. This may contribute to the great clinical variability observed in PXE patients. It is of important interest that ABCC6/MRP6-

deficiency has a remarkable effect on the gene expression of $A B C A$ subclass members. To date, $A B C A 1$ is the best characterized member of this subclass. It is mainly involved in HDL biosynthesis and cholesterol efflux. ${ }^{39,40}$ Polymorphisms in the ABCA1 were associated with cardiovascular disease and low plasma HDL levels. ${ }^{41-43}$ Wang et al previously reported that plasma HDL concentrations varied in a PXE patient and carriers of the ABCC6/MRP6 polymorphisms p.R1268Q. ${ }^{44}$ Furthermore, abcc6 knockout mice developed a $25 \%$ reduction in plasma HDL cholesterol. ${ }^{8} A B C A 3$ is a regulator of lamellar body metabolism and was reported to form lipid containing vesicles in human embryonic kidney cells. ${ }^{45}$ Little is known about the physiological function of the ABCA6-like transporters including $A B C A 6, A B C A 9$, $A B C A 10$. The members of this subclass were reported to be regulated by cholesterol inversely to $A B C A 1$ and therefore to act in opposed pathways. ${ }^{42}$ Gene expression of $A B C A 1$ was previously shown to be positively and negatively regulated by products of the mevalonate pathway in different cell lines, as well in dermal fibroblasts. ${ }^{46}$ This pathway supplies polyisoprenoid-conjugates as percursors to further synthesize dolichol, menaquinone (vitamin $\mathrm{K}_{\mathrm{n}}$ ), tocopherol, ubichinone and finally cholesterol. ${ }^{47}$ It was previously hypothesized that vitamin K-conjugates might be possible ABCC6 substrates. ${ }^{48}$

We further observed enhanced $A B C C 2$ gene expression in PXE patients samples; in female NHDFs and, most notably, in HDFs from female PXE patients (data not shown). These results are consistent with a previous study reporting gender differences in $a b c c 2 / \mathrm{mrp} 2 \mathrm{mRNA}$ and protein expression in a mouse model for chronic kidney disease. ${ }^{49} A b c c 2 / \mathrm{mrp} 2$, $a b c c 3 / \mathrm{mrp} 3$ and $a b c c 4 / \mathrm{mrp} 4$ expression in mice were also reported to be induced in the context of oxidative stress. ${ }^{50}$ Mild chronic oxidative stress might be involved in PXE manifestation. ${ }^{28}$ ABCC4/MRP4 and ABCC5/MRP5 were demonstrated to transport cyclic nucleotides and nucleotide analogs, even if controversial results were obtained regarding the strength of substrate affinity. ${ }^{51}$ Moreover, both transporters were thought to serve as overflow pumps under 

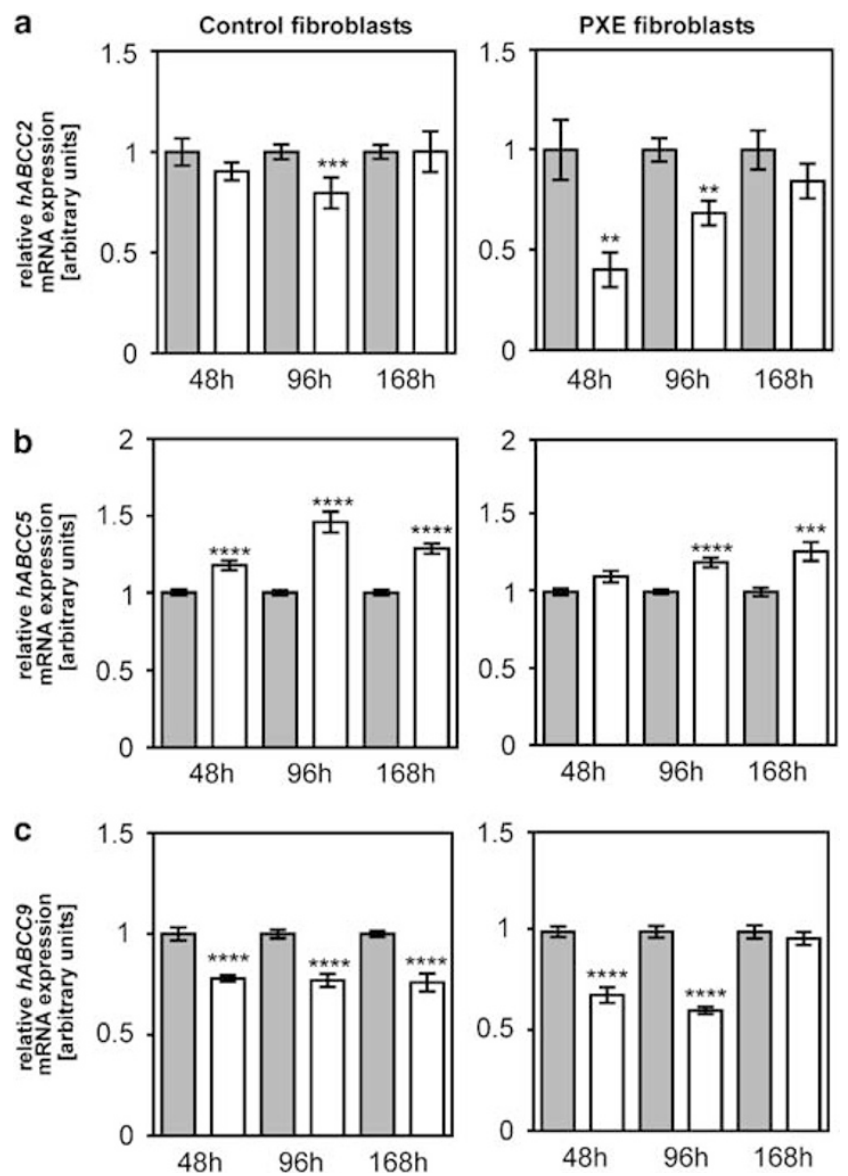

Figure 6 Effect of siRNA-mediated knockdown of $A B C C 6$ gene expression on gene expression of $A B C C$ transporter proteins. (a) $A B C C 2$, (b) $A B C C 5$ and (c) $A B C C$. Experiments were performed with HDFs from healthy controls $(n=4)$ and PXE fibroblasts $(n=2)$. Gray bars: cell cultures transfected with a scramble siRNA-negative control; white bars: $A B C C 6$-specific siRNAtransfected HDFs. Data are presented in arbitrary units as means with corresponding standard error at time points 48,96 and $168 \mathrm{~h}$. ${ }^{* *} P<0.01$; ${ }^{* * *} P<0.001 ;{ }^{* * * * P}<0.0001$.

conditions where cGMP synthesis was impaired. ${ }^{52}$ Induction of $A B C C 4$ and $A B C C 5$ gene expression suggests an increase in cAMP and cGMP accumulation/efflux due to MRP6 deficiency in PXE. In contrast to the other members of subclass C, $A B C C 9 /$ sulfonylurea receptor (SUR) 2 has no identified transport function. SURs are ATP-sensitive potassium ion channels which form dimers with other postassium-channels of the $\mathrm{K}_{\mathrm{IR}}$-family. SURs are typical $\mathrm{ABC}$ transporter proteins due to their topology, and various compounds were demonstrated to modulate their activity as phosphoinositides and long-chain acyl coenzyme A derived from fatty acids. ${ }^{53}$ The fact that most of the genes with altered expression due to $A B C C 6 / \mathrm{MRP} 6$ deficiency belong to the ABCA subclass points to a role of $A B C C 6 / \mathrm{MRP} 6$ in lipid metabolism. This assumption is underlined by the identification of $A B C C 9 /$ SUR2 as further candidate in PXE pathogenesis since $A B C C 9$ is also affected by intermediates of lipid biosynthesis.
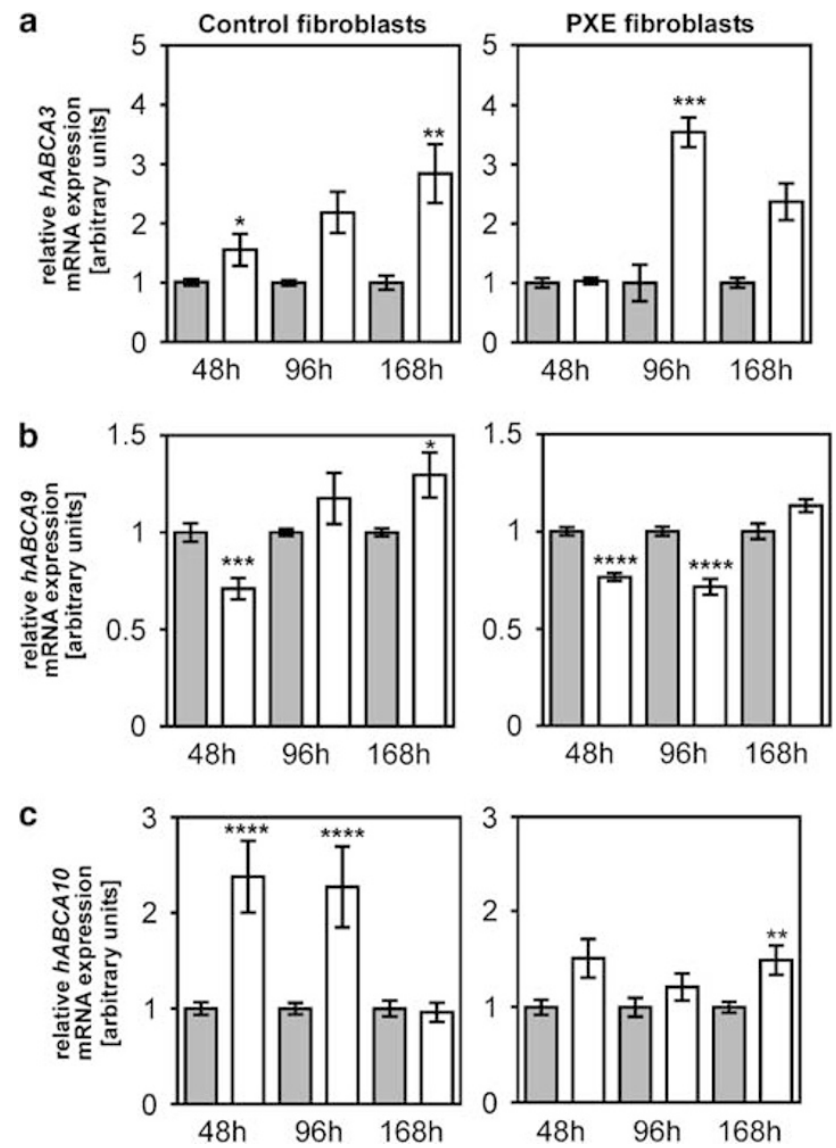

Figure 7 Effect of siRNA-mediated knockdown of $A B C C 6$ gene expression on gene expression of $A B C A$ transporter proteins. (a) $A B C A 3$, (b) $A B C A 9$ and (c) $A B C A 10$. Experiments were performed with HDFs from healthy controls $(n=4)$ and PXE fibroblasts $(n=2)$. Gray bars: cell cultures transfected with a scramble siRNA-negative control; white bars: $A B C C 6$-specific siRNAtransfected HDFs. Data are presented in arbitrary units as means with corresponding standard error at time points 48,96 and $168 \mathrm{~h} .{ }^{\star} P<0.05$; ${ }^{* *} P<0.01 ;{ }^{* * * P}<0.001 ;{ }^{* * * * P}<0.0001$.

Our study design has several limitations due to the small sample size used and our major focus on investigating transcript levels. It is noteworthy that protein expression was not investigated due to study limitations, these may differ from mRNA expression. So, our new findings have to be confirmed on the level of protein expression which was behind the scope of our study. In order to investigate whether the impaired gene expression profile is really caused by MRP6 deficiency, and not by the high interindividual variability, we impaired $A B C$ C6/MRP6 activity in vitro. Therefore, we knocked down ABCC6/MRP6 mRNA and protein expression by using target-specific siRNA to further analyze the influence of MRP deficiency on gene expression of other $A B C$ transporter proteins and lineage markers of PXE manifestation. Indeed, specific downregulation of $A B C C 6$ gene expression led to increased gene expression of the PXE marker genes ELN and SOD2. We further observed increased gene 
expression of $A B C A 3, A B C A 9$ and $A B C A 10$ which corroborated the result from former experiments. In contrast, gene expression of $A B C C 2, A B C C 9$ and $A B C A 6$ was controversially reduced. This needs to be further clarified and might be just due to off-target effects of siRNA silencing on highly homologous $\mathrm{ABC}$ transporter genes.

To our surprise, we observed similar siRNA-mediated effects on the gene expression profile in ABCC6/MRP6-deficient cells. To the best of our knowledge, siRNA silencing of target genes that cause genetic disorders has never been performed in cells, whose target expression is already disturbed. Therefore, it is quite difficult to evaluate the obtained results. The observed gene expression changes might be just due to off-target effects often mediated by siRNA silencing, particularly, in case of the PXE lineage markers ELN and $S O D 2$ that are affected by several conditions, including stress. Besides we could detect small amounts of ABCC6 amplicons by performing standard PCRs pointing to a basal or residual ABCC6 gene expression in PXE fibroblasts (data not shown). Hence, another possibility is that also residual target gene expression might be affected by siRNA silencing leading to an intensification of an already existing phenotype. These concerns have to be clarified for instance by performing complementation studies and using further ABCC6-specific siRNA oligonucleotides targeting other sequences of the ABCC6 mRNA.

Our results show that the use of siRNA to downregulate ABCC6/MRP6 expression might be helpful for investigating PXE pathogenesis in cell culture models but that this strategy also reveals several limitations. We found no effect on the MRP efflux activity analyzing silenced control fibroblasts. The ABCC6/MRP6 knockdown mediated by siRNA might be accompanied by residual MRP6 protein. Moreover, we cannot exclude that $A B C C 6$-specific siRNA has important off-target effects on other genes, particularly on highly homologues genes thus explaining the controversial results, especially obtained when analyzing samples from early time points after silencing. However, the usage of $A B C C 6$-specific siRNA to knockdown $A B C C 6 / \mathrm{MRP} 6$ gene and protein expression is a valuable tool to determine what happens within the cell and to investigate the molecular mechanisms leading to PXE manifestation. Using different cell donors takes into account varying genetic backgrounds, which is important to detect common pathomechanisms induced by ABCC6/MRP6 deficiency. Therefore, our experimental design might be helpful in explaining the great clinical variability in PXE manifestation.

The observations of our study further support a role for $A B C$ C6/MRP6 in transporting metabolites of sterol biosynthesis, as these function as important regulators of ABCA transporters. Many characteristic pathobiochemical hallmarks seen in PXE may arise from pathological changes in lipid metabolism, for instance, calcification, oxidative stress and enhanced matrix protein synthesis. It will be of great interest to uncover a possible role for $A B C C 6 / \mathrm{MRP} 6$ in this important metabolic pathway as this would be a major step toward disclosing the possible physiological substrate of ABCC6/MRP6.

\section{ACKNOWLEDGEMENTS}

We thank Manfred Haas, Veronika Schulz, Alexandra Adam and Christoph Lichtenberg for their excellent technical assistance and Sarah L Kirkby for her linguistic advice. We are very grateful to all the PXE patients, whose cooperation made this study possible. Furthermore, we thank Peter Hof, chairman of the Selbsthilfegruppe für PXE-Erkrankte Deutschlands 1999 e.V., and the members of the clinical outpatients department for PXE at the Bethesda hospital in Freudenberg, Germany. This work was supported by a grant from the 'Stiftung für Pathobiochemie und Molekulare Diagnostik' of the Deutsche Vereinte Gesellschaft für Klinische Chemie und

Laboratoriumsmedizin.

\section{DISCLOSURE/CONFLICT OF INTEREST}

The authors declare no conflict of interest.

1. Kool $M$, van der Linden $M$, de Haas $M$, et al. Expression of human MRP6, a homologue of the multidrug resistance protein gene MRP1, in tissues and cancer cells. Cancer Res 1999;59:175-182.

2. Bergen AA, Plomp AS, Schuurman EJ, et al. Mutations in ABCC6 cause pseudoxanthoma elasticum. Nat Genet 2000;25:228-231.

3. Le Saux O, Urban Z, Tschuch C, et al. Mutations in a gene encoding an $A B C$ transporter cause pseudoxanthoma elasticum. Nat Genet 2000;25:223-227.

4. Ringpfeil F, Lebwohl MG, Christiano AM, et al. Pseudoxanthoma elasticum: mutations in the MRP6 gene encoding a transmembrane ATP-binding cassette $(A B C)$ transporter. Proc Natl Acad Sci USA 2000;97:6001-6006.

5. Neldner K, Struk B. Pseudoxanthoma elasticum. In: Royce PM, Steinmann B (eds). Connective Tissue and its Heritable Disorders. Wiley-Liss Inc.: New York, 2002, pp 561-583.

6. Schulz V, Hendig D, Henjakovic $M$, et al. Mutational analysis of the ABCC6 gene and the proximal ABCC6 gene promoter in German patients with pseudoxanthoma elasticum (PXE). Hum Mutat 2006;27:831.

7. Klement JF, Matsuzaki Y, Jiang QJ, et al. Targeted ablation of the abcc6 gene results in ectopic mineralization of connective tissues. Mol Cell Biol 2005;25:8299-8310.

8. Gorgels TG, Hu X, Scheffer GL, et al. Disruption of Abcc6 in the mouse: novel insight in the pathogenesis of pseudoxanthoma elasticum. Hum Mol Genet 2005;14:1763-1773.

9. Haimeur A, Conseil G, Deeley RG, et al. The MRP-related and $\mathrm{BCRP} / \mathrm{ABCG} 2$ multidrug resistance proteins: biology, substrate specificity and regulation. Curr Drug Metab 2004;5:21-53.

10. Deeley RG, Westlake C, Cole SP. Transmembrane transport of endo- and xenobiotics by mammalian ATP-binding cassette multidrug resistance proteins. Physiol Rev 2006;86:849-899.

11. Scheffer GL, Hu X, Pijnenborg AC, et al. MRP6 (ABCC6) detection in normal human tissues and tumors. Lab Invest 2002;82:515-518.

12. Jiang $Q$, Uitto J. Pseudoxanthoma elasticum: a metabolic disease? J Invest Dermatol 2006;126:1440-1441.

13. Madon J, Hagenbuch B, Landmann L, et al. Transport function and hepatocellular localization of mrp6 in rat liver. Mol Pharmacol 2000;57:634-641.

14. Götting C, Hendig D, Adam A, et al. Elevated xylosyltransferase I activities in pseudoxanthoma elasticum (PXE) patients as a marker of stimulated proteoglycan biosynthesis. J Mol Med 2005;83:984-992.

15. Hendig D, Schulz V, Arndt $M$, et al. Role of serum fetuin-A, a major inhibitor of systemic calcification, in pseudoxanthoma elasticum. Clin Chem 2006;52:227-234.

16. Le Saux O, Bunda S, VanWart CM, et al. Serum factors from pseudoxanthoma elasticum patients alter elastic fiber formation in vitro. J Invest Dermatol 2006;126:1497-1505.

17. Gheduzzi D, Boraldi F, Annovi G, et al. Matrix Gla protein is involved in elastic fiber calcification in the dermis of pseudoxanthoma elasticum patients. Lab Invest 2007;87:998-1008. 
18. Jiang $\mathrm{Q}$, Li Q, Uitto J. Aberrant mineralization of connective tissues in a mouse model of pseudoxanthoma elasticum: systemic and local regulatory factors. J Invest Dermatol 2007;127:1392-1402.

19. Li Q, Jiang Q, Schurgers LJ, et al. Pseudoxanthoma elasticum: reduced gamma-glutamyl carboxylation of matrix gla protein in a mouse model (Abcc6-/-). Biochem Biophys Res Commun 2007;364:208-213.

20. Meng $\mathrm{H}$, Vera I, Che $\mathrm{N}$, et al. Identification of Abcc6 as the major causal gene for dystrophic cardiac calcification in mice through integrative genomics. Proc Natl Acad Sci USA 2007;104: 4530-4535.

21. Jiang $Q$, Dibra F, Wang K, et al. Cell-based therapy for Pseudoxanthoma elasticum: reduction of connective tissue mineralization in a mouse model $\left(\mathrm{Abcc6}^{--}\right)$by transplantation of wild-type hepatocytes. J Invest Dermatol 2008, (Abstract).

22. Jiang $Q$, Endo $M$, Dibra $F$, et al. Pseudoxanthoma elasticum is a metabolic disease. J Invest Dermatol 2008.

23. Uitto J, Pulkkinen L, Ringpfeil F. Molecular genetics of pseudoxanthoma elasticum: a metabolic disorder at the environmentgenome interface? Trends Mol Med 2001;7:13-17.

24. Hu X, Peek R, Plomp A, et al. Analysis of the frequent R1141X mutation in the ABCC6 gene in pseudoxanthoma elasticum. Invest Ophthalmol Vis Sci 2003;44:1824-1829.

25. Quaglino D, Boraldi F, Barbieri D, et al. Abnormal phenotype of in vitro dermal fibroblasts from patients with Pseudoxanthoma elasticum (PXE). Biochim Biophys Acta 2000;1501:51-62.

26. Passi $A$, Albertini $R$, Baccarani Contri $M$, et al. Proteoglycan alterations in skin fibroblast cultures from patients affected with pseudoxanthoma elasticum. Cell Biochem Funct 1996;14:111-120.

27. Quaglino D, Sartor L, Garbisa S, et al. Dermal fibroblasts from pseudoxanthoma elasticum patients have raised MMP-2 degradative potential. Biochim Biophys Acta 2005;1741:42-47.

28. Pasquali-Ronchetti I, Garcia-Fernandez MI, Boraldi F, et al. Oxidative stress in fibroblasts from patients with pseudoxanthoma elasticum: possible role in the pathogenesis of clinical manifestations. J Pathol 2006;208:54-61.

29. Belinsky MG, Chen ZS, Shchaveleva I, et al. Characterization of the drug resistance and transport properties of multidrug resistance protein 6 (MRP6, ABCC6). Cancer Res 2002;62:6172-6177.

30. Ilias A, Urban Z, Seidl TL, et al. Loss of ATP-dependent transport activity in pseudoxanthoma elasticum-associated mutants of human ABCC6 (MRP6). J Biol Chem 2002;277:16860-16867.

31. Boraldi F, Quaglino D, Croce MA, et al. Multidrug resistance protein- 6 (MRP6) in human dermal fibroblasts. Comparison between cells from normal subjects and from pseudoxanthoma elasticum patients. Matrix Biol 2003;22:491-500.

32. Hirohashi T, Suzuki H, Ito K, et al. Hepatic expression of multidrug resistance-associated protein-like proteins maintained in eisai hyperbilirubinemic rats. Mol Pharmacol 1998;53:1068-1075.

33. Kuroda M, Kobayashi Y, Tanaka Y, et al. Increased hepatic and renal expressions of multidrug resistance-associated protein 3 in Eisai hyperbilirubinuria rats. J Gastroenterol Hepatol 2004;19:146-153.

34. Li Q, Jiang Q, Larusso J, et al. Targeted ablation of Abcc1 or Abcc3 in Abcc6(-/-) mice does not modify the ectopic mineralization process. Exp Dermatol 2007;16:853-859.

35. Christiano AM, Lebwohl MG, Boyd CD, et al. Workshop on pseudoxanthoma elasticum: molecular biology and pathology of the elastic fibers. Jefferson Medical College, Philadelphia, Pennsylvania, June 10, 1992. J Invest Dermatol 1992;99:660-663.
36. Lebwohl M, Neldner K, Pope FM, et al. Classification of pseudoxanthoma elasticum: report of a consensus conference. J Am Acad Dermatol 1994:30:103-107.

37. Langmann T, Mauerer R, Schmitz G. Human ATP-binding cassette transporter TaqMan low-density array: analysis of macrophage differentiation and foam cell formation. Clin Chem 2006;52:310-313.

38. Vandesompele J, De Preter K, Pattyn F, et al. Accurate normalization of real-time quantitative RT-PCR data by geometric averaging of multiple internal control genes. Genome Biol 2002;3:research0034.1-0034.11.

39. Bodzioch M, Orso E, Klucken J, et al. The gene encoding ATP-binding cassette transporter 1 is mutated in Tangier disease. Nat Genet 1999:22:347-351.

40. Lawn RM, Wade DP, Garvin MR, et al. The Tangier disease gene product $\mathrm{ABC1}$ controls the cellular apolipoprotein-mediated lipid removal pathway. J Clin Invest 1999;104:R25-R31.

41. Brousseau ME, Bodzioch M, Schaefer EJ, et al. Common variants in the gene encoding ATP-binding cassette transporter 1 in men with low $\mathrm{HDL}$ cholesterol levels and coronary heart disease. Atherosclerosis 2001;154:607-611.

42. Wenzel JJ, Piehler A, Kaminski WE. ABC A-subclass proteins: gatekeepers of cellular phospho- and sphingolipid transport. Front Biosci 2007;12:3177-3193.

43. Frikke-Schmidt $R$, Nordestgaard $B G$, Jensen $G B$, et al. Genetic variation in $A B C$ transporter $A 1$ contributes to $\mathrm{HDL}$ cholesterol in the general population. J Clin Invest 2004;114:1343-1353.

44. Wang J, Near S, Young K, et al. ABCC6 gene polymorphism associated with variation in plasma lipoproteins. J Hum Genet 2001;46:699-705.

45. Nagata $\mathrm{K}$, Yamamoto $\mathrm{A}$, Ban N, et al. Human ABCA3, a product of a responsible gene for abca3 for fatal surfactant deficiency in newborns, exhibits unique ATP hydrolysis activity and generates intracellular multilamellar vesicles. Biochem Biophys Res Commun 2004;324: 262-268.

46. Denis $M$, Bissonnette $R$, Haidar $B$, et al. Expression, regulation, and activity of ABCA1 in human cell lines. Mol Genet Metab 2003;78: 265-274.

47. Goldstein JL, Brown MS. Regulation of the mevalonate pathway. Nature 1990;343:425-430.

48. Borst $P$, van de Wetering $K$, Schlingemann R. Does the absence of ABCC6 (Multidrug Resistance Protein 6) in patients with Pseudoxanthoma elasticum prevent the liver from providing sufficient vitamin K to the periphery? Cell Cycle 2008;7:1575-1579.

49. Lu H, Klaassen C. Gender differences in mRNA expression of ATPbinding cassette efflux and bile acid transporters in kidney, liver, and intestine of 5/6 nephrectomized rats. Drug Metab Dispos 2008:36:16-23.

50. Maher JM, Dieter MZ, Aleksunes LM, et al. Oxidative and electrophilic stress induces multidrug resistance-associated protein transporters via the nuclear factor-E2-related factor-2 transcriptional pathway. Hepatology 2007:46:1597-1610.

51. Borst $P$, de Wolf $C$, van de Wetering $K$. Multidrug resistance-associated proteins 3, 4, and 5. Pflugers Arch 2007;453:661-673.

52. Wielinga PR, van der Heijden I, Reid G, et al. Characterization of the MRP4- and MRP5-mediated transport of cyclic nucleotides from intact cells. J Biol Chem 2003;278:17664-17671.

53. Bryan J, Munoz A, Zhang $X$, et al. $A B C C 8$ and $A B C C 9$ : $A B C$ transporters that regulate K+ channels. Pflugers Arch 2007;453:703-718.

54. Livak KJ, Schmittgen TD. Analysis of relative gene expression data using real-time quantitative PCR and the 2(-Delta Delta $C(T)$ ) method. Methods 2001;25:402-408. 